\title{
Putting the learner at the centre: Quality in adult learning and education
}

\section{Paul Stanistreet ${ }^{1}$}

Published online: 26 November 2019

(c) UNESCO Institute for Lifelong Learning and Springer Nature B.V. 2019

This month, the UNESCO Institute for Lifelong Learning (UIL) launches its fourth Global Report on Adult Learning and Education (GRALE 4). ${ }^{1}$ The report, published every three years, tracks countries' progress against the commitments made on adult education in the Belém Framework for Action (BFA), ${ }^{2}$ agreed at the Sixth International Conference on Adult Education (CONFINTEA VI) in 2009. The 2019 report shows that, a decade on from CONFINTEA VI, participation in adult learning and education (ALE) is not where it needs to be; not if countries are to achieve the Sustainable Development Goal on education (SDG 4) or realise the huge potential contribution ALE can make to the other SDGs. Improvements are urgently required to increase and widen participation in ALE, particularly among vulnerable and marginalised groups, and to ensure that provision is of a high quality. As GRALE 4 makes clear, provision is where "the rubber meets the road", where the different factors contributing to effective teaching and learning come together and the impact of ALE is felt. Participation in adult education can only support fair, inclusive and sustainable development if quality is ensured and provision effectively addresses the needs, hopes and aspirations of adult learners.

GRALE 4 shows that while three-quarters of responding countries report progress in the quality of ALE in areas such as curricula, assessment, teaching methods and employment conditions, these improvements are not evenly spread. While countries noted progress in the quality of literacy and basic skills and continuing training and professional development, progress in community and citizenship education was negligible. Only 2 per cent of 11 responding countries reported progress in developing quality criteria for curricula in citizenship education, for example, and no more

\footnotetext{
${ }^{1}$ UIL (2019). Leave no one behind: Participation, equity and inclusion. 4th Global Report on Adult Learning and Education (GRALE 4). Hamburg: UNESCO Institute for Lifelong Learning.

${ }^{2}$ UIL (UNESCO Institute for Lifelong Learning). (2010). Belém framework for action: Harnessing the power and potential of adult learning and education for a viable future. Hamburg: UIL. Retrieved 21 November 2019 from https://unesdoc.unesco.org/ark:/48223/pf0000187789?posInSet=2\&query $\mathrm{Id}=4 \mathrm{bdb} 196 \mathrm{a}-\mathrm{c} 2 \mathrm{cf}-4914-\mathrm{a} 7 \mathrm{~d} 0-\mathrm{b} 33 \mathrm{cdc} 72425 \mathrm{~b}$.
}

Paul Stanistreet

p.stanistreet@unesco.org

1 UNESCO Institute for Lifelong Learning, Hamburg, Germany 
than 3 per cent of countries reported progress for any of the quality indicators for this field of learning. Of course, the data collected in GRALE 4 do not tell us how quality is understood in different countries, or the base level from which progress is charted. However, the snapshot this report provides suggests strongly that, where progress is being made, it is not consistently applied across all areas of learning, or all areas of quality. The lack of headway in education for active citizenship is especially troubling as it plays such an important part in promoting and protecting democracy, freedom, equality, human rights, tolerance and solidarity, as well as in empowering learners to make positive changes in their own communities.

As the BFA makes clear, "Quality in learning and education is a holistic, multidimensional concept and practice and demands constant attention and continuous development" (UIL 2010, p. 8). It requires "relevant content and modes of delivery, learner-centred needs assessment, the acquisition of multiple competences and knowledge, the professionalisation of educators, the enrichment of learning environments and the empowerment of individuals and communities" (ibid., pp. 8-9). The BFA highlights that quality demands both a learner-centred approach that reflects the diversity of learners' needs and aspirations, and "support to systematic interdisciplinary research and adult learning and education, complemented by knowledge management systems for the collection, analysis and dissemination of data and good practice" (ibid., p. 9). GRALE 4 shows not only that some learners' needs are given different weighting than others, but also that, in very many cases, we simply do not know enough about what works and what does not, particularly for typically excluded groups such as migrants and refugees, adults with disabilities and people living in remote rural locations. Engaging with traditionally hard-to-reach groups often demands a different approach, and a sensitive understanding of different home, work, social and cultural contexts.

This is the focus of the first article of this issue, by Elizabeth Aanuoluwapo Ajayi, on "The role of traditional folklore in facilitating adult learning in Nigeria". Ajayi notes that conventional ALE facilitation methods in Nigeria frequently fail to meet the needs and expectations of adult learners or to motivate them to engage fully in a course. To change this situation and improve the learning outcomes of provision, she argues, demands a more creative approach that listens to learners and takes their prior knowledge and experience into account. One viable approach, applicable in Nigeria but in principle applicable to the facilitation of formal, informal and nonformal adult learning in any society, she suggests, is to introduce traditional folklore and methods of knowledge transmission into ALE facilitation. This approach, as Ajayi describes it, has the double benefit not only of engaging adults in learning, tapping into the language and repertoire of concepts and ideas with which they first engaged with the world, but also of encouraging a greater appreciation of traditional forms of knowledge, both in the classroom and in wider society. The fascinating description she gives of how this approach can be applied in practice provides the reader with a hopeful sense of how ALE can connect a learner's experience and knowledge with their future aspirations and purposes.

Noah Kenny Sichula and Gerhard Genis, in the second article in this issue, "Pedagogical practices in non-formal adult literacy classes in Zambia", also highlight the importance of taking a learner-centred approach. The authors' focus is on two 
non-formal literacy classes offered in the Katete District of Eastern Zambia: one provided by the Zambian government's Department of Community Development, the other by Tikondane, a non-governmental organisation (NGO). Both courses took a teacher-centred approach and followed a lecture-style format. Sichula and Genis found that while this approach, applied in a participatory manner, was capable of producing considerable learning gains, the students would have benefited more from a learner-centred approach that recognised and valued their knowledge, experience and agency rather than seeking merely to correct a perceived deficiency. Most of the facilitators viewed the learners as "illiterate and ignorant" and consequently applied pedagogical practices that did not reflect contemporary views of literacy as "multiple situated and social practices" (Street 2014). ${ }^{3}$ The authors argue instead for a holistic approach to adult literacy learning that reconceptualises literacy in a way that matches contemporary understandings of the term and that is genuinely learnercentred, in line with international standards for instructional methods.

"Competency-based curriculum development in the informal sector: The case of sewing skills training in rural South India", by Muthuveeran Ramasamy and Matthias Pilz, also emphasises the importance of focusing on the needs and motives of learners, particularly those from disadvantaged or marginalised groups. The article examines a sewing skills training course for women in rural India and explores the extent to which "a competency-based curriculum development approach can respond to the skills training needs of people (seeking to be) employed in the informal sector". The authors describe how the curriculum for this course was developed on the basis of learner demand, and assess its subsequent piloting in four villages in South India. The chief advantage of competency-based training is that it is flexible in terms of duration, content and method, while enabling the curriculum to be tailored to the specific demands of the target group. Ramasamy and Pilz found that curriculum development in the informal sector works best when the targeted learners are directly involved in its planning and development. The course in question not only took the leaners' abilities, needs/interests and motivation into consideration, but also "kept them central to the process", ensuring curriculum, instruction and assessment were aligned with the trainees' expectations, needs and experience. The competency-based approach to curriculum development clearly has a much wider application, as the authors suggest, particularly in engaging hard-to-reach adults in education and learning and ensuring they stay on board.

The fourth article in this issue, "An analysis of theoretical perspectives that define adult learners for effective and inclusive adult education policies", by Yaw Owusu-Agyeman, considers some of the same issues, but from a different perspective: that of the policymaker. The author analyses five theoretical frameworks used to define adult learners in relation to formal, non-formal and informal learning modes: human capital, adult development, sociocultural, political and biographical. He shows how these frameworks can enhance effective and inclusive adult education policies and practices at different levels of governance,

\footnotetext{
3 Street, V. B. (2014). Social literacies: Critical approaches to literacy in development, ethnography and education. New York: Routledge.
} 
with particular reference to Africa. The article concludes that by reflecting on the five theoretical perspectives (rather than outmoded historical or traditional approaches), and considering lifelong learning both as a concept focused on the development of education policy and as the process whereby people learn throughout their lives, policymakers can improve the policies and practices that guide adult learners in lifelong learning environments and promote inclusive education.

Richard Desjardins, in his article, "The labour market benefits of adult education from a global perspective", shows the huge potential benefits of offering adult education that is genuinely inclusive and effective. Reviewing recent international evidence on the labour market outcomes of adult education, he demonstrates that, though fragmented and incomplete, it nevertheless supports the view that adult education has positive impacts on a wide range of labour market outcomes, including through enhanced employment and career prospects; improved performance and earnings; greater job satisfaction and commitment to work; and more innovative capacities. However, despite such evidence being widespread, public spending on adult education remains low in most countries - an issue also highlighted in GRALE 4, which indicates that funding is inadequate and calls on countries to do more. Desjardins discusses a number of important contextual and structural factors that are helpful in contextualising and interpreting the evidence and for understanding the reasons for underinvestment in adult education. In his conclusion, he highlights the need to foster a balanced evidence base to inform policy, as well as to institutionalise flexible and diversified adult education provision structures that recognise and value all kinds of adult education and learning. A strong emphasis on vocational training and the labour market, without recognition of learning undertaken for personal or social reasons, he argues, can act as a barrier to learning, particularly for disadvantaged adults.

The issue concludes with a case study from the Republic of Korea, one of the countries often held up as an exemplar of successful policy and investment in adult learning and education. In their article "The Academic Credit Bank System in the Republic of Korea: An effective medium for lifelong learning in higher education?" Hyewon Park, Jinhee Choi, JungHwan Kim and Jihee Hwang examine an open education system that has operated in the Republic of Korea since 1998. The Academic Credit Bank System (ACBS) was designed to provide both traditional-age and mature students with opportunities to earn academic qualifications, including Bachelor's degrees, at low cost and in collaboration with the traditional system. A key government lifelong learning initiative, it offers more flexible educational opportunities and has expanded access to education more generally, including to adults without post-school qualifications. However, as the authors note, despite its credit value and its rising number of graduates, an ACBS degree is still not considered to be equivalent to a traditional degree in the job market. Applying a critical lens, they find that ACBS is limited primarily with regard to social recognition and that this systemic limitation is an outcome of Korea's academic credentialism, which, in their view, tends to perpetuate students' social status. A non-formal learning domain cannot be successful, they contend, unless the credentials it produces are perceived as directly comparable to those acquired through traditional higher education routes. 
The low status and recognition of adult learning and education in comparison to other parts of the education system remains a barrier to realising its rich potential. Notwithstanding the wide benefits of ALE and the broad range of research attesting to them, some of it captured here, ALE remains a low priority in most countries, as GRALE 4 makes clear. In too many cases, it is under-funded, under-researched and under-understood. There are deep and persistent inequalities in ALE participation, both within and between countries, with vulnerable and disadvantaged groups faring worst. And even though participation is going up in many countries, progress is insufficient, given the social, economic, technological and environmental challenges we face. The articles in this issue demonstrate how effective ALE can be when it is offered flexibly and responsively, and when it is designed in a participatory way, with learners at the centre. Ensuring that it makes a full contribution to the 2030 Agenda for Sustainable Development means not only increasing participation but also improving quality across the board and in every area of learning, thus putting structures in place that, as Richard Desjardin puts it, "recognise and value all kinds of adult learning and education".

Publisher's Note Springer Nature remains neutral with regard to jurisdictional claims in published maps and institutional affiliations. 